\title{
Hippocampal and extrahippocampal systems compete for control of contextual fear: Role of ventral subiculum and amygdala
}

\author{
Joseph C. Biedenkapp and Jerry W. Rudy ${ }^{1}$ \\ Department of Psychology, Center for Neuroscience, University of Colorado, Boulder, Colorado 80309, USA
}

\begin{abstract}
Two neural systems, a hippocampal system and an extrahippocampal system compete for control over contextual fear, and the hippocampal system normally dominates. Our experiments reveal that output provided by the ventral subiculum is critical for the hippocampal system to win this competition. Bilateral electrolytic lesions of the ventral subiculum after conditioning, but not before conditioning, impaired contextual fear conditioning. Reversibly inactivating this region by bilateral injections of muscimol produced the same results-no impairment when the injection occurred prior to conditioning but a significant impairment when this region was inactivated after conditioning. Thus, the extrahippocampal system can support contextual fear conditioning if the ventral subiculum is disabled before conditioning but not if it is disabled after conditioning. Our experiments also reveal that the basolateral region of the amygdala (BLA) is where the two systems compete for associative control of the fear system. To test this hypothesis we reasoned that the extrahippocampal system would also acquire associative control over the fear system, even if the hippocampal system were functional, if the basal level of plasticity potential in the BLA could be increased. We did this by injecting the DI dopamine agonist, SKF82958, into the BLA just prior to conditioning. This treatment resulted in a significant increase in freezing when the ventral subiculum was disabled prior to the test. These results are discussed in relationship to the idea that DI agonists increase plasticity potential by increasing the pool of available extrasynaptic GluR1 receptors in the population of neurons supporting acquired fear.
\end{abstract}

It is generally believed that contextual fear conditioning depends on the hippocampus. However, it is now clear that an extrahippocampal system exists that can also support contextual fear conditioning. The last statement is based on the fact that damage to the hippocampus prior to conditioning has a minor impact on contextual fear (Maren et al. 1997; Frankland et al. 1998; Cho et al. 1999; Wiltgen et al. 2006). In fact, the conclusion that the hippocampus is normally involved in contextual fear conditioning is now based primarily on the finding that damage to the hippocampus after conditioning greatly impairs fear to the context in which conditioning occurs (Maren et al. 1997; Frankland et al. 1998; Anagnostaras et al. 1999; Bannerman et al. 1999; Richmond et al. 1999; Fanselow 2000; Rudy et al. 2004; Wiltgen et al. 2006).

Maren et al. (1997) were the first to appreciate the implications of this set of findings. Specifically, they proposed that (1) in the normal animal there is competition between the hippocampal system and an extrahippocampal system for support of contextual fear conditioning, and (2) the hippocampal system normally dominates the extrahippocampal system-preventing it from acquiring the information needed to support fear to the context. This competition hypothesis provides a reasonable account of the lesion data. If the hippocampus is damaged prior to conditioning, then the extrahippocampal system will be able to acquire control over the fear system and generate a fear response at the time of testing. However, if the hippocampal system is functional during conditioning, it will (1) acquire control of the fear system, and (2) prevent the acquisition of control by the extrahippocampal system. Thus, if the hippocampal system is damaged after conditioning, the expression of contextual fear will be impaired, because the information that was acquired by the hippocampal

'Corresponding author.

E-mail JRudy@Clipr.Colorado.edu; fax (303) 492-2967.

Article is online at http://www.learnmem.org/cgi/doi/10.1101//m.1099109. system will not be available and the extrahippocampal system never acquired the relevant information.

Maren et al.'s competition hypothesis is accepted by a number of other researchers (Wiltgen and Fanselow 2003; Rudy et al. 2004; Driscoll et al. 2005; Wiltgen et al. 2006). Nevertheless, very little is known about the mediators of this competition. The experiments in this study were aimed at filling some of the gaps in our knowledge of the neural basis of this competition. They are organized around two hypotheses:

- The ability of the hippocampal system to dominate the extrahippocampal system depends on information it provides through the ventral subiculum, a major output region of the hippocampus.

- The locus of the competition is the basolateral region of the amygdala (BLA), which is thought to be critical to the acquisition of conditioned fear and is where information from the hippocampal and extrahippocampal system can converge.

\section{Experiment 1. Contextual fear conditioning is impaired by damage to ventral subiculum after, but not before conditioning}

The ventral subiculum is the primary route by which the hippocampal system communicates with the amygdala to activate the fear system. It is also known to have outputs to neocortical areas, such as the entorhinal cortex as well as subcortical areas such as the nucleus accumbens (Naber and Witter 1998; Naber et al. 2000; Pitkanen et al. 2000). One clue that the ventral subiculum may be critical to the domination of the hippocampal system over the extrahippocampal system is provided by Maren (1999), who reported that damage to this region prior to conditioning had a negligible effect on contextual fear conditioning, but the same lesion after training produced a major impairment. This pattern of 
results is the same as described above for the effect of damage to the hippocampus and can be interpreted to mean that the output from the ventral subiculum is important in allowing the hippocampal to dominate the extrahippocampal system. Maren's (1999) lesions, however, were extensive and might be more accurately described as a relatively complete ventral hippocampus lesion that included damage to entorhinal cortex. Thus, the purpose of the experiment was to determine whether we could replicate Maren (1999), but with a slightly more restricted lesion.

\section{Results}

\section{Behavioral}

As shown in Figure 1, if anything, rats with damage to the ventral subiculum prior to conditioning displayed a modest increase in freezing to the conditioning context. In contrast, rats whose damage was produced after conditioning displayed impaired freezing. A $2 \times 2$ ANOVA revealed a reliable interaction between time of the lesion (before vs. after) and lesion condition (sham vs. lesion), $F_{(1,12)}=8.475 ; P<0.02$. Post-hoc analyses revealed a significant difference between rats with lesions and control rats when the lesion was made after conditioning $(P<0.05)$, but not when the lesion was made prior to conditioning. Thus, even with a more limited lesion, we replicated Maren et al.'s result-that damage to the ventral subiculum after, but not before conditioning, impairs contextual fear conditioning.

\section{Histology}

The extent of the maximal and minimal lesions to the ventral subiculum are presented in Figure 2. In all subjects, portions of the caudal and the majority of the rostral ventral subiculum were destroyed. We observed no damage to the entorhinal cortex. However, there was significant damage to the portions of the ventral hippocampus, including the CA1 region.

\section{Experiment 2. Contextual fear conditioning is impaired by muscimol injections into the ventral subiculum after, but not before conditioning}

The extrahippocampal system can support contextual fear when the ventral subiculum is damaged prior to conditioning, but not when the subiculum is functional. This conclusion suggests that the competition between the two systems takes place during the acquisition phase of the experiment. The purpose of the second experiment was to examine the implications of this hypothesis. To do this, we used the GABA-A agonist muscimol to re-

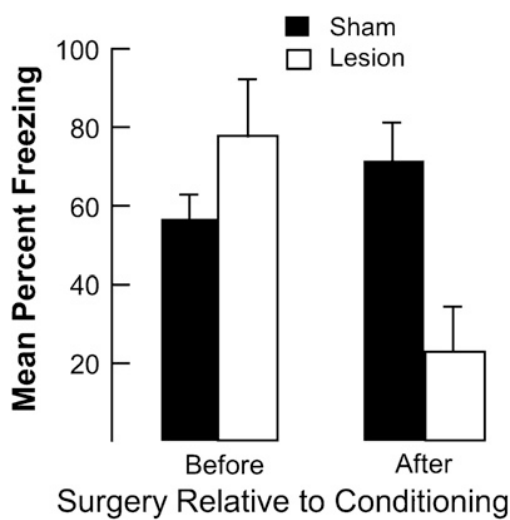

Figure 1. The results of Experiment 1. Note that damage to the ventral subiculum after, but not before conditioning, impairs freezing during the contextual fear test. Bars, SE.

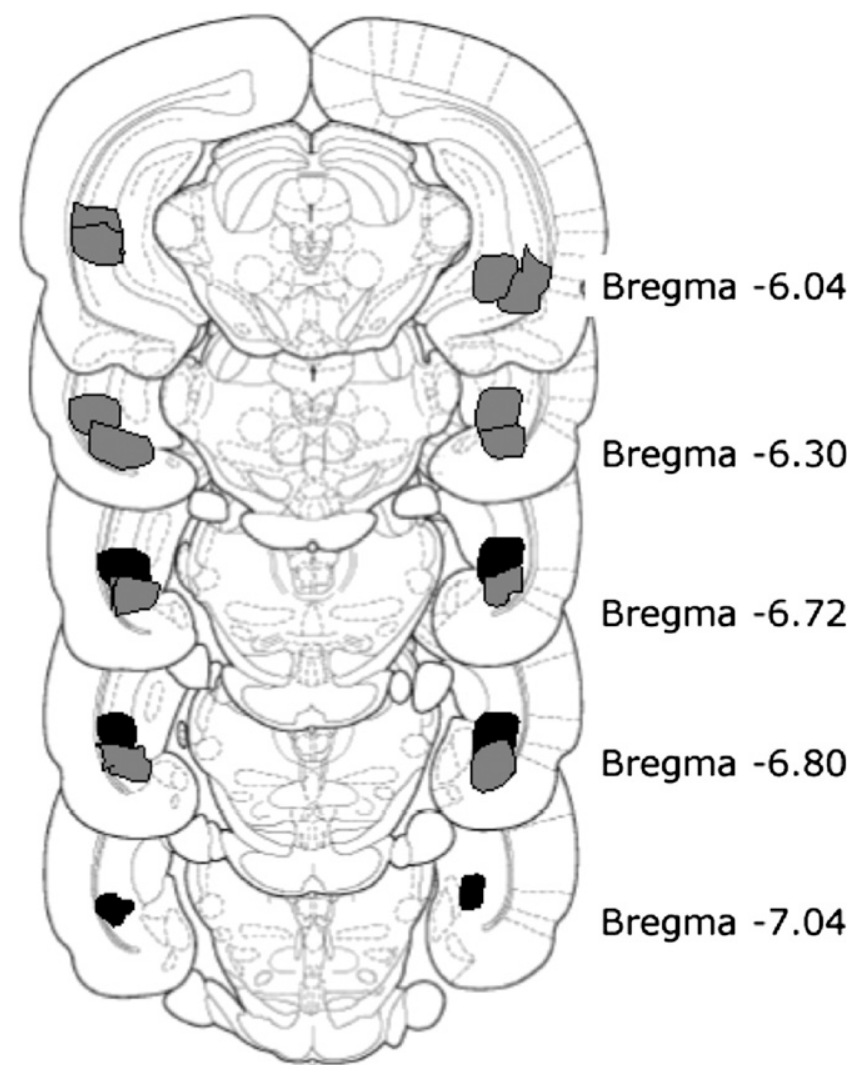

Figure 2. Schematic representation of the extent of lesions (maximum, light shading; minimum, dark shading). Coronal brain sections modified from Paxinos and Watson (1998).

versibly inactivate the ventral subiculum at different stages of the experiment.

If the competition occurs during acquisition then several predictions can be made. First, inactivation only during acquisition (the Muscimol/Vehicle condition) should not produce a deficit in contextual fear conditioning. This is because under these conditions the extrahippocampal system should acquire the information needed to support contextual fear, and this system does not need the ventral subiculum to activate the fear system during acquisition. Second, if the ventral subiculum is inactivated just at the time of retrieval (the Vehicle/Muscimol condition) there should be a significant impairment. This is because in this normal state, the hippocampal system will not only acquire the information needed to support contextual fear, but it will also prevent the extrahippocampal system from doing so. Thus, if the ventral subiculum is inactivated prior to retrieval, the information acquired by the hippocampal system would not be able to activate the fear system, and the extrahippocampal system would not contain the necessary information to do so. Finally, if the ventral subiculum is inactivated prior to both acquisition and retrieval (the Muscimol/Muscimol condition), there should be no impairment. This is because the extrahippocampal system should acquire the necessary information, and does not need the ventral subiculum to activate the fear system.

\section{Results}

\section{Behavioral}

As shown in Figure $3 \mathrm{~A}$ the results were consistent with the predictions. Note that only rats in the vehicle/musimol condition 
A
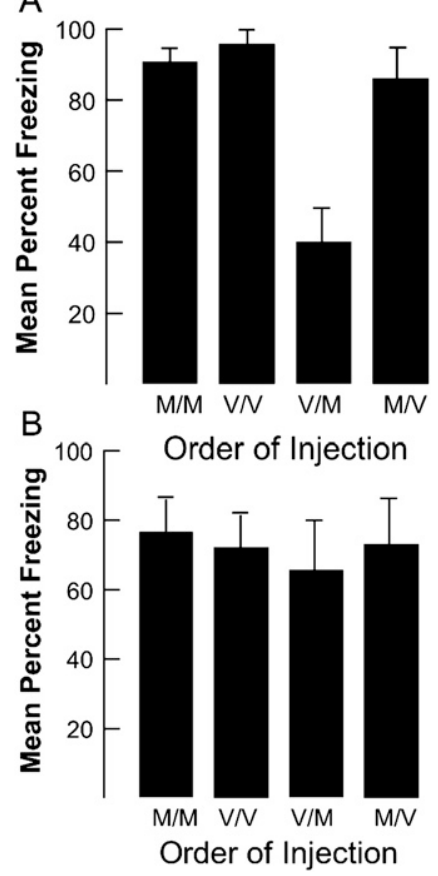

Figure 3. (A) The results of Experiment 2. Note that rats displayed impaired freezing if the vehicle was injected prior to training and muscimol was injected prior to testing (Condition V/M). However, if muscimol was injected prior to both conditioning and the retention test (Condition $\mathrm{M} / \mathrm{M}$ ) or just prior to conditioning (Condition $\mathrm{M} / \mathrm{V}$ ), rats were not impaired. This means that when the ventral subiculum is disabled before conditioning, the extrahippocampal system can support contextual fear conditioning. However, if this output system is functional at the time of conditioning, it prevents the extrahippocampal system from supporting contextual fear. $(B)$ The impairment in freezing when muscimol is injected prior to retention is reversible. Bars, SE.

were impaired relative to those in the control condition who were injected with the vehicle prior to both acquisition and retrieval. Injecting muscimol prior to acquisition had no effect on conditioning, independent of whether or not muscimol was injected prior to retrieval. A one-way ANOVA revealed a significant main effect for drug condition $\left(F_{(3,28)}=8.976 ; P<.005\right)$. Post-hoc analyses revealed a significant difference between V-M and all other groups $(P<.05)$. There were no other statistically significant differences among the groups.

Rats in the Vehicle/Muscimol condition displayed impaired contextual fear conditioning. However, if the acquisition hypothesis is correct, the hippocampal system should have acquired the information needed to support contextual fear, but could not express this information because its output to the amygdala was inactive. Thus, if tested drug free, the rats in this condition should show as much freezing as rats in the other conditions. To test this hypothesis, all rats were given a second context fear test the next day when in a drug-free state. As shown in Figure 3B, all groups displayed substantial freezing, and there were no differences among the groups $(F<1)$. This result confirms that the rats in the vehicle/muscimol group had captured the information needed to support contextual fear, and could express this information when the ventral subiculum was active.

\section{Histology}

Rats were eliminated if either cannula track was judged to be anterior to $-6.04 \mathrm{~mm}$ or posterior to $-7.04 \mathrm{~mm}$; lateral to $\pm 5.5 \mathrm{~mm}$ or medial to $\pm 4.5 \mathrm{~mm}$; or dorsal to $-5.5 \mathrm{~mm}$ or ventral to $-6.5 \mathrm{~mm}$.

\section{Experiment 3, A and B. The D1 agonist SKF-82958 rescues extrahippocampal contextual fear when injected into the BLA}

The previous experiments support the idea that the dominance of the hippocampal system in the competition to support contextual fear conditioning depends on output via the ventral subiculum. This raises two questions: (1) What are the components of the other extra-hippocampal system that can support contextual fear conditioning, and (2) what is the locus of the competition?

The hippocampus is situated in a neural system, whereby sensory information flows into associative areas of the neocortex and from there to areas of the medial temporal lobes (e.g., perirhinal cortex, postrhinal cortex, entorhinal cortex) and finally to the hippocampus (Burwell and Amaral 1998a,b; Burwell 2000; Squire et al. 2004; Anderson et aol. 2007; Furtak et al. 2007; Teyler and Rudy 2007).

It is possible that the medial temporal lobe regions, perirhinal and postrhinal cortices, which project forward to the hippocampus, are key components of the neural system that can support contextual fear when the hippocampus and/or its output region, the ventral subiculum, are removed. First, damage to either of these regions either before or after fear conditioning dramatically impairs contextual fear conditioning (Buffalo et al. 1999; Bucci et al. 2000, 2002; Lindquist et al. 2004). Note that this pattern of results differs from that associated with damage to either the hippocampus or ventral subiculum, because contextual fear conditioning is spared if the hippocampus or ventral subiculum is damaged before conditioning. Second, it is also the case that the perirhinal cortex projects to the lateral region of the amygdala, thereby allowing its inputs to that system to be modified to support fear conditioning (McDonald 1992, 1998; Faulkner and Brown 1999; Pitkanen et al. 2000). Third, these cortices project to the hippocampus (Eichenbaum 2000; Lavenex and Amaral 2000; Teyler and Rudy 2007) and provide it with the highly processed information it needs to participate in representing context. Thus, if these cortices are removed either before or after conditioning, the hippocampus would be deprived of the information it needs to make its contribution to contextual fear. So, even with the hippocampus intact, it could not support a contextual fear memory. Given all of this, it is reasonable to think that the perirhinal and postrhinal regions can substitute to some extent for a damaged hippocampal system.

Given that output from these medial temporal lobe regions and the hippocampus both converge on neurons in the basolateral region of the amygdala, it is also possible that this region is where the competition takes place. Thus, our hypothesis is that the hippocampus dominates the competition for associative connections to neurons in the BLA. To test this hypothesis, we reasoned that if this region could be stimulated to increase its ability to support these plasticity processes, then one could eliminate or reduce the ability of the hippocampal system to prevent projections from the extrahippocampal system from also associating with BLA neurons. This means that even when the hippocampal system is functioning, it should be possible for the extrahippocampal system to also acquire the connections it needs to support contextual fear.

To test this hypothesis, we took advantage of an observation by Guarraci et al. (1999), who found that injecting the dopamine D1-receptor agonist, SKF-82958, into the BLA, enhanced the resulting conditioned fear. This finding suggests that the D1receptor agonist had a metaplasticity effect (Abraham 2008), altering the basal plasticity potential of neurons in this region. Assume now that (1) hippocampal and extrahippocampal systems compete for some limited source of plasticity in the BLA regions, and (2) the D1-receptor agonist increases this source. If this is true, 
then it follows that if the agonist is injected into the BLA prior to conditioning, both the hippocampal and extrahippocampal system could support fear conditioning. Such an outcome would support the hypothesis that the BLA region is the location of competition. These assumptions and implications are presented in Figure 4. Two experiments were conducted to test this hypothesis.

\section{Results}

\section{Behavioral}

The purpose of the first experiment (Experiment 3A) was to insure that we could replicate the Guarraci et al. (1999) result that the D1 agonist, SKF-82958, facilitates fear conditioning. SKF-82958 or its vehicle was injected into the BLA region prior to contextual fear conditioning with a relatively weak 0.35 -mA foot shock. As shown in Figure 5, rats injected with the drug displayed enhanced freezing compared with rats injected with the vehicle, $F_{(1,19)}=$ $7.5, P=0.01$.

The second experiment (Experiment 3B) was designed to test our hypothesis that competition occurs in the BLA region. Either SKF-82958 (SKF) or vehicle was injected into the BLA region prior to conditioning. No drugs were injected into the ventral subiculum prior to training. However, prior to testing, muscimol or vehicle was injected into the ventral subiculum. As shown in Figure 6, when the vehicle was injected into the BLA prior to conditioning, we replicated the result reported in Experiment 2-inactivating the ventral subiculum prior to testing resulted in a reduced freezing response. In contrast, rats injected with SKF82958 into the BLA prior to conditioning and injected with muscimol prior to the test (the SKF/M condition) were not impaired. An ANOVA revealed significant differences among the groups, $F_{(2,28)}=5.1, P<0.05$. Post hoc comparisons found that rats in the $\mathrm{V} / \mathrm{M}$ condition differed from those in the control condition, $\mathrm{V}-\mathrm{V}$, and in the SKF/M condition $(P<.05)$. These results support the

\section{Plasticity Potential}

\section{Resulting Strength}

A

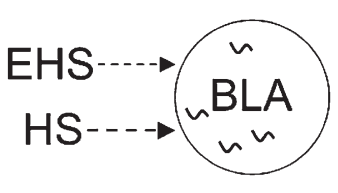

B

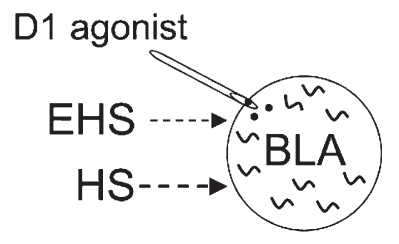

C

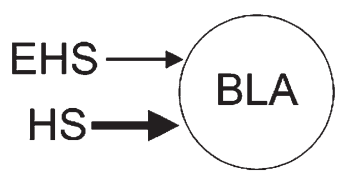

D

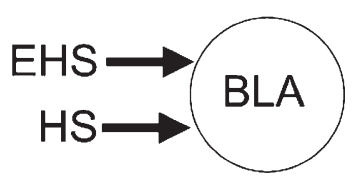

Figure 4. This figure represents the basic assumption and implications behind the use of a D1 agonist to test the hypothesis that the BLA is where the hippocampal system (HS) and extrahippocampal system (EHS) compete for associative control over the fear system. The left side of the figure represents the basal state of plasticity potential in the amygdala under normal conditions $(A)$, and when D1 agonists are injected into the amygdala $(B)$. The right side of the figure represents the resulting change in the strength of contextual fear associated with these two states after conditioning. In the normal state, output from the hippocampal system (via ventral subiculum) is expected to dominate the competition for available plasticity product needed to support the learning, as represented by the relative size of the arrow in $C$. The increased plasticity potential resulting from the D1 agonist is predicted to be large enough to support associated control to both the hippocampal and extrahippocampal systems, as represented in $D$.

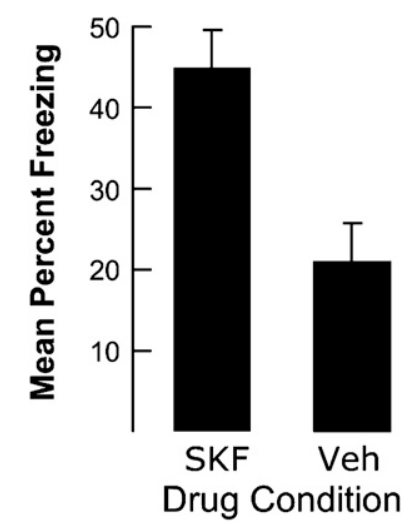

Figure 5. The results of Experiment $3 \mathrm{~A}$. Contextual fear conditioning is enhanced when the D1 agonist SKF-82958 is injecting into the BLA prior to conditioning. Bars, SE.

hypothesis that the hippocampal and extrahippocampal systems compete for a limited source of plasticity in the BLA, and that this source can be increased by the D1 agonist, SKF-82958.

\section{Histology}

In Experiment 3, A and B, in which the intent was to inject SKF82958 into the BLA, rats were eliminated from the experiment if either of the cannula track marks was anterior to $-2.8 \mathrm{~mm}$ or posterior to $-3.6 \mathrm{~mm}$; lateral to $\pm 5.5 \mathrm{~mm}$ or medial to $\pm 4.5 \mathrm{~mm}$; or dorsal to $-7.0 \mathrm{~mm}$ or ventral to $-9.0 \mathrm{~mm}$. In Experiment 3B, cannulae were also directed at both the BLA and ventral subiculum. Rats were eliminated if either cannula track was judged to be anterior to $-6.04 \mathrm{~mm}$ or posterior to $-7.04 \mathrm{~mm}$; lateral to $\pm 5.5 \mathrm{~mm}$ or medial to $\pm 4.5 \mathrm{~mm}$; or dorsal to $-5.5 \mathrm{~mm}$ or ventral to $-6.5 \mathrm{~mm}$.

\section{Discussion}

The first experiments were motivated by the hypothesis that output from the hippocampus provided by the ventral subiculum to other brain regions is critical to the dominance of the hippocampal system over the extrahippocampal system in the competition for acquired control over the fear system. In support of this hypothesis, the experiments revealed that contextual fear conditioning is impaired by a relatively small amount of damage to the ventral subiculum region after, but not before conditioning. Similarly, contextual fear conditioning was impaired when the ventral subiculum was inactivated after, but not before conditioning.

Although this conclusion is reasonable, it must be viewed with caution. Information is processed through the hippocampus to the ventral subiculum via pyramidal neurons in CA1 (Amaral et al. 1991). CA1 neurons are so proximal to ventral subiculum neurons that it is impossible for the methods we used, electrolytic lesions and pharmacology inactivation, to influence cells in the ventral subiculum without also influencing nearby CA1 neurons. Perhaps a more acceptable conclusion is that the dominance of the hippocampal system for control over the fear system depends on the CA1-ventral subiculum output component of the system.

\section{The two systems are not equivalent}

These experiments and others (Maren et al. 1997; Frankland et al. 1998; Cho et al. 1999; Fanselow 2000; Anagnostaras et al. 2001; Wiltgen et al. 2006) clearly indicate that there are two neural systems that can support contextual fear conditioning-one that contains the hippocampal formation and one that does not. The hippocampal system normally dominates, but the extrahippocampal system can substitute if the hippocampal system is disabled prior to training. One should not conclude, however, 


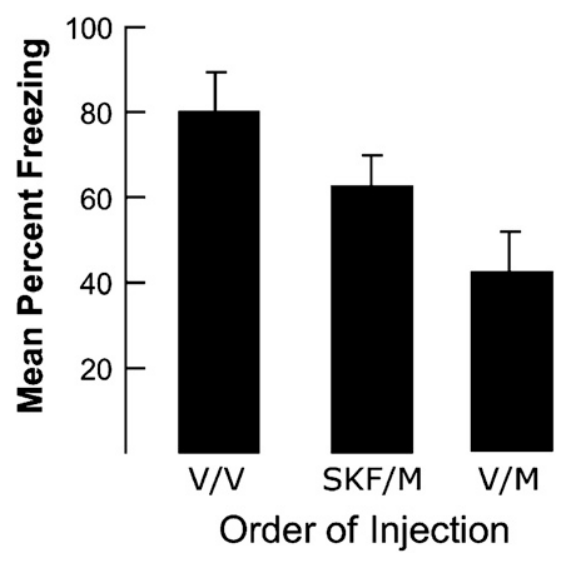

Figure 6. The results of Experiment $3 \mathrm{~B}$. Note first that rats that who did not receive an injection of SKF-82958 prior to conditioning were impaired if muscimol was injected into the ventral subiculum prior to the retention test (Condition V/M). This result replicates what was found in Experiment 2 and indicates the hippocampal system dominated the extrahippocampal system. However, this dominance was eliminated if the D1 agonist, SKF-82958, was injected into the BLA prior to training (Condition SKF/M). This result supports the hypothesis that BLA is where the two systems compete for control of the fear system.

that these two systems are equivalent in their ability to capture and process information about the context in which events are experienced. This point is clear when one considers the importance of the hippocampus for a phenomenon discovered by Fanselow (1990) called the context pre-exposure facilitation effect.

This phenomenon emerged from a Fanselow (1990) analysis of what is called the immediate shock effect. If a rat is shocked immediately or within a couple of seconds of being placed into a context, when later tested it shows almost no fear (as measured by freezing) in that context. However, Fanselow reported that if the rat is pre-exposed to that context the day before, then immediate shock produces significant conditioning (see also Westbrook et al. 1994). Based on these results, Fanselow (1990) concluded that immediate shock fails to produce conditioning because prior to the shock the rat had not sufficiently sampled the environment to acquire a representation of the context that could associate with shock. As a consequence of pre-exposure, the rat acquires a representation of the context and this retrieved representation is associated with the immediate shock.

The context pre-exposure facilitation effect clearly reveals that rats acquire a representation of an explored context. Moreover, Rudy and colleagues (Rudy and O'Reilly 1999; Rudy et al. 2002) have reported that this representation can be retrieved by cues associated with transporting the rat from its home cage to the context. In fact, if the rats are immediately shocked in a place they have never experienced, they will condition to the memory of the context retrieved by the transport cues and not to the place they were actually shocked.

These findings indicate that the neural system supporting the context pre-exposure facilitation effect can support a process called pattern completion-a portion of the experience that originally established the memory trace can activate or replay the entire experience. Many theorists assume that the hippocampus supports pattern completion and that this is how it makes a critical contribution to the episodic memory system (e.g., Marr 1971; Teyler and DiScenna 1986; Squire 1992; McClelland et al. 1995; Rudy et al. 2002; Matus-Amat et al. 2004; Teyler and Rudy 2007).

Thus, it is interesting that, unlike the case for contextual fear, it appears that the extrahippocampal system cannot support the context pre-exposure facilitation effect. This conclusion is based on several results, all of which reveal that disabling the hippocampus prior to exposing rats to the context eliminates or greatly reduces the context pre-exposure facilitation effect. These treatments include lesioning the dorsal hippocampus (Rudy et al. 2002) and inactivating this region (Matus-Amat et al. 2004). These results are important because they reveal that the extrahippocampal system cannot support the context pre-exposure facilitation effect and by inference, pattern completion.

A second phenomenon that discriminates the processes supported by the two systems is context-dependent object recognition. When normal rats are allowed to explore an object, they can later recognize it-when later allowed to explore it or a novel object, they will spend more time investigating the novel object. Normal rats also remember the context in which an object was explored; when they encounter that object in a different context, they investigate it more (as if it was novel) than if it is reexperienced in the original context. Rats with damage to the hippocampus also acquire a memory representation of an explored object, because they will spend more time investigating a novel object during the retention test. However, unlike normal rats, rats with damage to the hippocampus evidently do not remember the context in which they first explored the object, because when that object is represented in a different context they still treat it as familiar (Mumby et al. 2002; Eacott and Norman 2004; Eichenbaum et al. 2007). Thus, the extrahippocampal system evidently cannot support the processes linking the object representation to the representation of context. This process appears to require the hippocampus.

A third context-process-related phenomenon that differentiates the two systems is generalization. For example, Antoniadis and McDonald (2000) reported that rats with damage to the hippocampus prior to conditioning display contextual fear conditioning, but have difficulty discriminating between the shocked context and another similar context. Similarly, Frankland et al. (1998) reported that mice with prior hippocampal damage have difficulty learning to discriminate between two contexts, one pair with shock and the other with no shock. Thus, the hippocampal system appears to support a more detailed representation of context than the extrahippocampal system.

Given the above facts, one is forced to conclude that although the extrahippocampal system can to some extent substitute for the hippocampal system, the two systems are not equivalent. The hippocampal system supports a broader range of context-related processes than does the extrahippocampal system.

\section{The locus of competition and the role of dopamine}

The second set of experiments were motivated by our hypothesis that the BLA region was the place where the hippocampal and extrahippocampal systems compete for control over the fear system. We reasoned that if the BLA was the place, then the extrahippocampal system could gain more control if the basal level of neural plasticity in this region could be increased (by injecting a D1 agonist). The results supported this hypothesis. As noted, Guarraci et al. (1999) previously reported that fear conditioning could be enhanced by an injection of a D1 agonist. Our results replicated their findings and add that the same treatment also enhances the ability of the extrahippocampal to gain associative control over the fear system. It is important to note, however, that we are not claiming that increasing the level of neural plasticity in the BLA selectively enhanced fear conditioning supported by the extrahippocampal system. Enhanced plasticity associated with injecting the D1 agonist in the BLA should generally enhance conditioning to representations of all potential cues present at the time of shock.

This conclusion that activating D1 receptors in the BLA region enhances fear conditioning raises the question-by what 
mechanisms does the action of dopamine receptors produce this effect? D1 receptors are positively coupled to production protein kinase A (PKA) (Huang and Kandel 2007). Smith et al. (2005) have reported that activating this class of dopaminergic receptors stimulates local protein synthesis in dendrites. This is of interest because local protein synthesis has been linked to some forms of late-phase long-term potentiation (Steward and Worley 2002; Bradshaw et al. 2003; Sutton and Schuman 2005, 2006; Tsokas et al. 2005).

Smith et al. (2005) reported that GluR1, an AMPA receptor subunit, is one protein up-regulated by activating the D1/D5 class of dopaminergic receptors, and that there is also an increased incorporation of GluR1 at synaptic sites. Recently, Gao et al. (2006) also reported that brief exposure to a D1 agonist increased the surface expression of GluR1 containing AMPA receptors. They proposed that D1 receptors might promote LTP by increasing the size of the extrasynaptic GluR1 pool available to be trafficked into the synapse.

That D1 receptors may play a role in the synthesis and trafficking of GluR1 containing AMPA receptors is not only important for LTP but also for fear memories. Rumpel et al. (2005) have reported that a fear conditioning experience traffics GluR1 receptors into synapses in the BLA. Moreover, they also reported that interfering with the trafficking of these receptors significantly reduced the resulting level of fear conditioning. Thus, the insertion of GluR1 containing AMPA receptors into synapses appears to be an important step toward establishing long-term fear memories.

Given these facts, it is reasonable to propose that the D1 agonist facilitated extrahippocampal system control over the fear system by increasing the pool of locally synthesized extrasynaptic GluR1 subunits that can be trafficked into the spines of neurons in the BLA in response to the conditioning experience. In principle, this could provide a mechanism for increasing the basal level of plasticity in this region of the brain needed for the extrahippocampal system to support contextual fear.

\section{Conclusions}

In summary, our experiments support two new hypotheses: (1) The dominance of the hippocampal system in the competition for contextual control over the fear system depends on output to the amygdala provided by the CA1-ventral subiculum region, and (2) the BLA is where the two systems compete. In addition, the experiments revealed that injecting the D1 dopamine agonist, SKF-82958, into the BLA region attenuated dominance by the hippocampal system over the extrahippocampal system-perhaps by increasing the pool of locally synthesized extrasynaptic GluR1 subunits that can be trafficked into the spines of neurons in the BLA in response to the conditioning experience.

\section{Materials and Methods}

\section{Subjects}

Adult male Sprague-Dawley rats weighing 250-300 g were used for all experiments. Rats were housed in pairs at $22^{\circ} \mathrm{C}$ on a $12: 12 \mathrm{~h}$ light:dark cycle with ad libitum access to food and water and allowed 1 wk to acclimate to colony conditions. All experiments were conducted with protocols approved by the University of Colorado Animal Care and Use Committee.

\section{Ventral subiculum lesions}

All lesions were made under halothane anesthesia. An incision was made at midline and the skull exposed. Holes were drilled through the skull above the intended lesion site. Electrolytic lesions were made with monopolar electrodes. A total of $1.5 \mathrm{~mA}$ of DC was passed through the electrode for a duration of $20 \mathrm{sec}$ at each of two sites in the ventral subiculum: AP, -6.7 and -6.3 ; ML, $+/-5.0$; DV, -7.0. Control subjects are under anesthesia for the same duration as the lesion animals. After the site was lesioned, drill holes in the skull were filled with bone wax, the wound was stapled, and an antibiotic ointment was applied to the wound. Rats were placed in a heated plastic recovery box and returned to their home cage once they recovered from anesthesia.

\section{Ventral subiculum and amygdala cannulations}

Under halothane anesthesia, animals were placed into a stereotaxic apparatus (David Kopf Instruments) and stainless-steel guide cannulae (Plastics One) were implanted bilaterally into the ventral subiculum. Based on the rat brain atlas of Paxinos and Watson (1998), the following coordinates were used for bilateral ventral subiculum cannulations: anteroposterior (AP), $-6.7 \mathrm{~mm}$; mediolateral $(\mathrm{ML}),+/-5.0 \mathrm{~mm}$; dorsoventral (DV), $-5.0 \mathrm{~mm}$, relative to bregma. Cannulae were fixed to the skull with dental acrylic and three small screws. To maintain patency, after surgery, an obturator was placed into the guide cannula that extended $1 \mathrm{~mm}$ beyond the tip of the guide cannula. For Experiment 3B, cannulae were implanted bilaterally into both the ventral subiculum and amygdala. Ventral subiculum coordinates were the same as above, the amygdala coordinates were AP: $-2.8 \mathrm{~mm}$, ML: $+/-4.8, \mathrm{DV}:-7.5$. Rats were allowed to recover for $7-10 \mathrm{~d}$ before conditioning.

\section{Microinjections}

Rats were gently wrapped in a soft towel, the obturator was removed, and a 33-gauge microinjector (Plastics One) attached to polyethylene 50 (PE50) tubing was inserted through the indwelling guide cannula. The distal end of the PE50 tubing was attached to a $10-\mu \mathrm{L}$ (Hamilton) syringe that mounted on a microinjection unit (model 5000; David Kopf Instruments) that accurately dispensed the desired volume, which was injected over 2 $\mathrm{min}$. The microinjector remained in place for an additional $1 \mathrm{~min}$ following the infusion. Muscimol, obtained from Sigma, was microinjected bilaterally in the ventral subiculum at a concentration of $0.5 \mu \mathrm{g} / \mu \mathrm{L}, 1.0 \mu \mathrm{L}$ total vol. One microliter of the D1 agonist, SKF-82958, was microinjected into the amygdala bilaterally at a concentration of $1.0 \mu \mathrm{g} / \mu \mathrm{L}$. Vehicle controls received equivolume sterile saline.

\section{Histology}

At the completion of the experiment, animals were anaesthetized with Fatal Plus $(50 \mathrm{mg} / \mathrm{kg}$ ) and decapitated, their brains removed, and frozen in cold isopentane. Coronal sections (40- $\mu \mathrm{m}$ thick) were taken through the structure of interest with a cryostat at $-20^{\circ} \mathrm{C}$ and mounted on glass slides. Sections were stained with cresyl violet and examined with light microscopy to verify lesion or cannula location. Only rats with lesions or cannula in the proper location were included for analysis.

\section{Apparatus}

The conditioning context was one of two identical ice chests $(54 \mathrm{~L} \times$ $30 \mathrm{~W} \times 27 \mathrm{H} \mathrm{cm}$ ) with white interiors. A speaker and an activated $24 \mathrm{~V}$ DC light bulb were mounted on the ceiling of each chest. A clear plastic window $(30 \mathrm{~L} \times 18 \mathrm{~W} \mathrm{~cm})$ was cut into the door so that the rats could be observed. The conditioning chambers $(26 \mathrm{~L} \times 21 \mathrm{~W} \times 24 \mathrm{H} \mathrm{cm})$ placed inside each chest were made of clear plastic and had window screen tops. The 2 -sec, $1.5-\mathrm{mA}$ or $0.35-\mathrm{mA}$ shock was delivered through a removable floor of stainless-steel rods $(1.5 \mathrm{~mm}$ diameter) spaced $1.2 \mathrm{~cm}$ center-tocenter (Model E10-30SR, Coulbourn Instruments). Each rod was wired to a shock source and scrambler (Model H13-16, Coulbourn Instruments). Each chamber was cleaned with water before each animal was conditioned or tested.

\section{Procedures for specific experiments}

\section{Experiment 1}

In the anterograde lesion condition, rats received lesions $1 \mathrm{wk}$ prior to conditioning. In the retrograde lesion condition, rats were 
conditioned and received lesions $24 \mathrm{~h}$ later. They were tested $1 \mathrm{wk}$ following the lesion. On Day 1, rats were placed in the conditioning chambers for $5 \mathrm{~min}$ and allowed to freely explore the context. On Day 2, rats were placed back into the conditioning context for $2 \mathrm{~min}$, after which they received a 2 -sec, $1.5-\mathrm{mA}$ foot shock; the animals were immediately removed and returned to their home cage. On Day 3 (Day 9 in the retrograde condition), rats were tested for their fear of the conditioning context. In all experiments, freezing, the rat's natural response to anticipated danger (Blanchard and Blanchard 1969), was the measure of conditioned fear. Using a sampling procedure, each rat was judged as either freezing or active every $10 \mathrm{sec}$ at that instant. Freezing was defined as the absence of all movement except for respiration. The test period lasted $5 \mathrm{~min}$. All scoring was conducted by an observer who had no knowledge of the rat's treatment history.

\section{Experiment 2}

On Day 1, rats were placed in the conditioning chambers for $5 \mathrm{~min}$ and allowed to freely explore the context. On Day 2, rats were injected with muscimol $(0.5 \mu \mathrm{g} / 1.0 \mu \mathrm{L} / \mathrm{side})$ or saline into the ventral subiculum $1 \mathrm{~h}$ prior to conditioning. Conditioning consisted of $2 \mathrm{~min}$ of context exploration followed by a single $1.5-\mathrm{mA}$, 2 -sec foot shock. The rats were immediately removed and returned to their home cage. On Day 3, rats were injected with muscimol $(0.5 \mathrm{ug} / 1.0 \mu \mathrm{L} / \mathrm{side})$ or saline into the ventral subiculum $1 \mathrm{~h}$ prior to the retrieval test. This resulted in four groups: Vehicle/Vehicle, Vehicle/Muscimol, Muscimol/Vehicle, Muscimol/Muscimol. To test whether muscimol inactivation was reversible, rats were tested again in a drug-free state $24 \mathrm{~h}$ later.

\section{Experiment $3 A$}

On Day 1, 5 min prior to conditioning, rats were injected with the D1 agonist SKF-82958 $(1.0 \mu \mathrm{g} / 1.0 \mu \mathrm{L} / \mathrm{side})$ or saline into the amygdala. Conditioning consisted of 2 min of context exploration, followed by a single $0.35-\mathrm{mA}, 2$-sec foot shock. The rats were immediately removed and returned to their home cage. The next day rats were tested for fear of the context.

\section{Experiment 3B}

On Day 1, rats were placed in the conditioning chambers for $5 \mathrm{~min}$ and allowed to freely explore the context. On Day 2, 5 min prior to conditioning, rats were injected with the D1 agonist SKF-82958 $(1.0 \mu \mathrm{g} / 1.0 \mu \mathrm{L} / \mathrm{side})$ or saline into the amygdala. Conditioning consisted of $2 \mathrm{~min}$ of context exploration, followed by a single 1.5$\mathrm{mA}, 2$-sec foot shock. The rats were immediately removed and returned to their home cage. On Day 3, rats were injected with muscimol $(0.5 \mu \mathrm{g} / 1.0 \mu \mathrm{L} / \mathrm{side})$ or saline into the ventral subiculum $1 \mathrm{~h}$ prior to the retrieval test.

\section{Acknowledgments}

We thank Karli Wright-Hardesty, Patricia Matus-Amat, Kyle Rolofson, and Amy Fisher for their excellent technical assistance. This research was supported by National Institutes of Health grant NIH RO1 MH61316 to J.W.R.

\section{References}

Abraham, W.C. 2008. Metaplasticity: Tuning synapses and networks for plasticity. Nat. Rev. Neurosci. 9: 387. doi: 10.1028/nrn2356.

Amaral, D.G., Dolorfo, C., and Alvarez-Royo, P. 1991. Organization of CA1 projections to the subiculum: A PHA-L analysis in the rat. Hippocampus 1: $415-435$

Anagnostaras, S.G., Maren, S., and Fanselow, M.S. 1999. Temporally graded retrograde amnesia of contextual fear after hippocampal damage in rats: Within-subjects examination. J. Neurosci. 19: 1106-1114.

Anagnostaras, S.G., Gale, G.D., and Fanselow, M.S. 2001. Hippocampus and contextual fear conditioning: Recent controversies and advances. Hippocampus 11: 8-17.

Anderson, P., Morris, R., Amaral, D., Bliss, T., and Okeefe, J., ed. 2007. The hippocampus book. Oxford University Press, New York.

Antoniadis, E.A. and McDonald, R.J. 2000. Amygdala, hippocampus, and discrimination fear conditioning to context. Behav. Brain Res. 108: 1-19.
Bannerman, D.M., Yee, B.K., Good, M.A., Heupel, M.J., Iversen, S.D., and Rawlins, J.N. 1999. Double dissociation of function within the hippocampus: A comparison of dorsal, ventral, and complete hippocampal cytotoxic lesions. Behav. Neurosci. 113: 1170-1188.

Blanchard, R.J. and Blanchard, D.C. 1969. Crouching as an index of fear. J. Comp. Physiol. Psychol. 67: 370-375.

Bradshaw, K.D., Emptage, N.J., and Bliss, T.V. 2003. A role for dendritic protein synthesis in hippocampal late LTP. Eur. J. Neurosci. 18: 3150-3152.

Bucci, D.J., Phillips, R.G., and Burwell, R.D. 2000. Contributions of postrhinal and perirhinal cortex to contextual information processing. Behav. Neurosci. 114: 882-894.

Bucci, D.J., Saddoris, M.P., and Burwell, R.D. 2002. Contextual fear discrimination is impaired by damage to the postrhinal or perirhinal cortex. Behav. Neurosci. 116: 479-488.

Buffalo, E.A., Ramus, S.J., Clark, R.E., Teng, E., Squire, L.R., and Zola, S.M. 1999. Dissociation between the effects of damage to perirhinal cortex and area TE. Learn. Mem. 6: 572-599.

Burwell, R.D. 2000. The parahippocampal region: Corticocortical connectivity. Ann. N. Y. Acad. Sci. 911: 25-42.

Burwell, R.D. and Amaral, D.G. 1998a. Cortical afferents of the perirhinal, postrhinal, and entorhinal cortices of the rat. J. Comp. Neurol. 398: 179-205.

Burwell, R.D. and Amaral, D.G. 1998b. Perirhinal and postrhinal cortices of the rat: Interconnectivity and connections with the entorhinal cortex. J. Comp. Neurol. 391: 293-321.

Cho, Y.H., Friedman, E., and Silva, A.J. 1999. Ibotenate lesions of the hippocampus impair spatial learning but not contextual fear conditioning in mice. Behav. Brain Res. 98: 77-87.

Driscoll, I., Howard, S.R., Prusky, G.T., Rudy, J.W., and Sutherland, R.J. 2005 Seahorse wins all races: Hippocampus participates in both linear and non-linear visual discrimination learning. Behav. Brain Res. 164: 29-35.

Eacott, M.J. and Norman, G. 2004. Integrated memory for object, place, and context in rats: A possible model of episodic-like memory? J. Neurosci. 24: $1948-1953$.

Eichenbaum, H. 2000. A cortical-hippocampal system for declarative memory. Nature Reviews Neurosci. 1: 41-50.

Eichenbaum, H., Yonelinas, A.R., and Ranganath, C. 2007. The medial temporal lobe and recognition memory. Annu. Rev. Neurosci. 30: 123152.

Fanselow, M.S. 1990. Factors governing one trial contextual conditioning. Anim. Learn. Behav. 18: 264-270.

Fanselow, M.S. 2000. Contextual fear, gestalt memories, and the hippocampus. Behav. Brain Res. 110: 73-81.

Faulkner, B. and Brown, T.H. 1999. Morphology and physiology of neurons in the rat perirhinal-lateral amygdala area. J. Comp. Neurol. 411: 613642.

Frankland, P.W., Cestari, V., Filipkowski, R.K., McDonald, R.J., and Silva, A.J. 1998. The dorsal hippocampus is essential for context discrimination but not for contextual conditioning. Behav. Neurosci. 112: 863-874.

Furtak, S.C., Wei, S.M., Agster, K.L., and Burwell, R.D. 2007. Functional neuroanatomy of the parahippocampal region in the rat: The perirhinal and postrhinal cortices. Hippocampus 17: 709-722.

Gao, C., Sun, X., and Wolf, M.E. 2006. Activation of D1 dopamine receptors increases surface expression of AMPA receptors and facilitates their synaptic incorporation in cultured hippocampal neurons. J. Neurochem. 98: $1664-1677$.

Guarraci, F.A., Frohardt, R.J., and Kapp, B.S. 1999. Amygdaloid D1 dopamine receptor involvement in Pavlovian fear conditioning. Brain Res. 827: 28-40.

Huang, Y.Y. and Kandel, E.R. 2007. Low-frequency stimulation induces a pathway-specific late phase of LTP in the amygdala that is mediated by PKA and dependent on protein synthesis. Learn. Mem. 14: 497-503.

Lavenex, P. and Amaral, D.G. 2000. Hippocampal-neocortical interaction: A hierarchy of associativity. Hippocampus 10: 420-430.

Lindquist, D.H., Jarrard, L.E., and Brown, T.H. 2004. Perirhinal cortex supports delay fear conditioning to rat ultrasonic social signals. $J$. Neurosci. 24: 3610-3617.

Maren, S. 1999. Neurotoxic or electrolytic lesions of the ventral subiculum produce deficits in the acquisition and expression of Pavlovian fear conditioning in rats. Behav Neurosci. 113: 283-290.

Maren, S., Aharonov, G., and Fanselow, M.S. 1997. Neurotoxic lesions of the dorsal hippocampus and Pavlovian fear conditioning in rats. Behav. Brain Res. 88: 261-274.

Marr, D. 1971. Simple memory: A theory for archicortex. Philos. Trans. $R$. Soc. Lond. B Biol. Sci. 262: 23-81.

Matus-Amat, P., Higgins, E.A., Barrientos, R.M., and Rudy, J.W. 2004. The role of the dorsal hippocampus in the acquisition and retrieval of context memory representations. J. Neurosci. 24: 2431-2439.

McClelland, J.L., McNaughton, B.L., and O'Reilly, R.C. 1995. Why there are complementary learning systems in the hippocampus and neocortex: Insights from the successes and failures of connectionist models of learning and memory. Psychol. Rev. 102: 419-457. 
McDonald, A.J. 1992. Projection neurons of the basolateral amygdala: A correlative Golgi and retrograde tract tracing study. Brain Res. Bull. 28: $179-185$.

McDonald, A.J. 1998. Cortical pathways to the mammalian amygdala. Prog. Neurobiol. 55: 257-332.

Mumby, D.G., Gaskin, S., Glenn, M.J., Schramek, T.E., and Lehmann, H. 2002. Hippocampal damage and exploratory preferences in rats: Memory for objects, places, and contexts. Learn. Mem. 9: 49-57.

Naber, P.A. and Witter, M.P. 1998. Subicular efferents are organized mostly as parallel projections: A double-labeling, retrograde-tracing study in the rat. J. Comp. Neurol. 393: 284-297.

Naber, P.A., Witter, M.P., and Lopes Silva, F.H. 2000. Networks of the hippocampal memory system of the rat. The pivotal role of the subiculum. Ann. N. Y. Acad. Sci. 911: 392-403.

Paxinos, G. and Watson, C. 1998. The rat brain in stereotaxic coordinates, 4th ed. Academic Press, San Diego, CA..

Pitkanen, A., Pikkarainen, M., Nurminen, N., and Ylinen, A. 2000. Reciprocal connections between the amygdala and the hippocampal formation, perirhinal cortex, and postrhinal cortex in rat. A review. Ann. N. Y. Acad. Sci. 911: 369-391.

Richmond, M.A., Yee, B.K., Pouzet, B., Veenman, L., Rawlins, J.N., Feldon, J., and Bannerman, D.M. 1999. Dissociating context and space within the hippocampus: Effects of complete, dorsal, and ventral excitotoxic hippocampal lesions on conditioned freezing and spatial learning. Behav. Neurosci. 113: 1189-1203.

Rudy, J.W. and O'Reilly, R.C. 1999. Contextual fear conditioning, conjunctive representations, pattern completion, and the hippocampus. Behav. Neurosci. 113: 867-880.

Rudy, J.W., Barrientos, R.M., and O'Reilly, R.C. 2002. Hippocampal formation supports conditioning to memory of a context. Behav. Neurosci. 116: $530-538$.

Rudy, J.W., Huff, N.C., and Matus-Amat, P. 2004. Understanding contextual fear conditioning: Insights from a two-process model. Neurosci. Biobehav. Rev. 28: 675-685.

Rumpel, S., LeDoux, J., Zador, A., and Malinow, R. 2005. Postsynaptic receptor trafficking underlying a form of associative learning. Science 308: $83-88$.
Smith, W.B., Starck, S.R., Roberts, R.W., and Schuman, E.M. 2005. Dopaminergic stimulation of local protein synthesis enhances surface expression of GluR1 and synaptic transmission in hippocampal neurons. Neuron 45: 765-779.

Squire, L.R. 1992. Memory and the hippocampus: A synthesis from findings with rats, monkeys, and humans. Psychol. Rev. 99: 195-231.

Squire, L.R., Stark, C.E., and Clark, R.E. 2004. The medial temporal lobe. Annu. Rev. Neurosci. 27: 279-306.

Steward, O. and Worley, P. 2002. Local synthesis of proteins at synaptic sites on dendrites: Role in synaptic plasticity and memory consolidation? Neurobiol. Learn. Mem. 78: 508-527.

Sutton, M.A. and Schuman, E.M. 2005. Local translational control in dendrites and its role in long-term synaptic plasticity. J. Neurobiol. 64: $116-131$.

Sutton, M.A. and Schuman, E.M. 2006. Dendritic protein synthesis, synaptic plasticity, and memory. Cell 127: 49-58.

Teyler, T.J. and DiScenna, P. 1986. The hippocampal memory indexing theory. Behav. Neurosci. 100: 147-154.

Teyler, T.J. and Rudy, J.W. 2007. The hippocampal indexing theory and episodic memory: Updating the index. Hippocampus 17: 1158-1169.

Tsokas, P., Grace, E.A., Chan, P., Ma, T., Sealfon, S.C., Iyengar, R., Landau, E.M., and Blitzer, R.D. 2005. Local protein synthesis mediates a rapid increase in dendritic elongation factor $1 \mathrm{~A}$ after induction of late longterm potentiation. J. Neurosci. 25: 5833-5843.

Westbrook, R.F., Good, A.J., and Kiernan, M.J. 1994. Effects of the interval between exposure to a novel environment and the occurrence of shock on the freezing responses of rats. Q. J. Exp. Psychol. B 47: 427-446.

Wiltgen, B.J. and Fanselow, M.S. 2003. A model of hippocampalcortical-amygdala interactions based on contextual fear conditioning. In The neurobiology of spatial behavior (ed. K.J. Jeffery), pp. 81-103. Oxford Press, New York.

Wiltgen, B.J., Sanders, M.J., Anagnostaras, S.G., Sage, J.R., and Fanselow, M.S. 2006. Context fear learning in the absence of the hippocampus. J. Neurosci. 26: 5484-5491.

Received June 11, 2008; accepted in revised form October 16, 2008. 


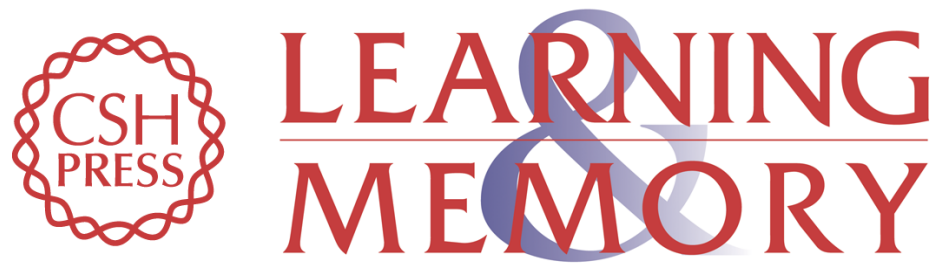

\section{Hippocampal and extrahippocampal systems compete for control of contextual fear: Role of ventral subiculum and amygdala}

Joseph C. Biedenkapp and Jerry W. Rudy

Learn. Mem. 2009, 16:

Access the most recent version at doi:10.1101//m.1099109

References This article cites 56 articles, 10 of which can be accessed free at: http://learnmem.cshlp.org/content/16/1/38.full.htmI\#ref-list-1

License

Email Alerting

Receive free email alerts when new articles cite this article - sign up in the box at the Service top right corner of the article or click here. 